\title{
Optimization of the typical environmental problem based on energy conservation and emission reduction
}

\author{
Baoyou Liu ${ }^{1}$, Wangtao ${ }^{2}$ \\ College of Environmental Science and Engineering, Hebei University of Science and Technology, \\ Shijiazhuang, 050018, China \\ Pollution prevention biotechnology laboratory of Hebei Province, Shijiazhuang, 050018, China \\ 1email: Iby7150@sina.com, ²email:723854478@qq.com
}

Keywords:environmental problem; optimization; energy conservation and emission reduction; air pollution; MATLAB

Abstract: A better project can always be obtained by system optimization of the typical environmental problems. In order to explore the optimal schedule arrangement, an operational research model based on the shortest path problem is put forward and resolved by MATLAB. The results showed that the whole trip distance of optimized schedule is $20689 \mathrm{~km}$, which reduced $12.08 \%$ compared with that of a random schedule arrangement. At the same time, 2.16175 tons of fuel can be saved and $6.50525 \mathrm{~kg}$ of $\mathrm{SO}_{2}$ can be reduced. The study has certain guiding significance for relevant department in making environmental protection plan.

\section{Introduction}

The quality of surrounding environment is increasingly concerned by people which is closely related to their own life, and the atmosphere quality is especially widely concerned as the rapid development of society. The main sources of air pollution are industrial pollution, traffic pollution , construction pollution and so on. To improve air quality, form the aspect of transportation, we can develop our technology and management deeply, such as improve the quality of oil products on technology, improve the auto combustion mode and equip with exhaust gas purification device.From the aspect of management, traffic restrictions are selected to reduce air pollution. As a technology method to provide the optimization schedule for the green transportation, system optimized can save energy, shorten time and improve efficiency. Providing best solutions for travel, the experiment aims to reduce toxic and harmful substance such as dioxide emissions, connecting economy with environment and achieving the goal of green travel.

\section{Problem Proposition}

A football match will be held in Beijing, Shanghai, Tianjin and Chongqing respectively. Home and away double round robin would be selected as rules in the match and home court is located in the home city. Considering the convenience of travel, coaches are designated vehicles and expenses shall be borne by the organizers.

A team will come to another city to participate in next game after they finish a game and they finally take back to their city. The distance between all cities follows as table1.

1.1Whether to find a optimal schedule to get the shortest distance and how many is the fuel quantity and the discharge of $\mathrm{SO}_{2}$.

1.2 Game organizing committee arranges a plan randomly (Table2), how long is the distance and the discharge of $\mathrm{SO}_{2}$ reduction compared with the optimal solutions. 
Table 1. Mileage between cities

\begin{tabular}{ccc}
\hline City & City & distance $(\mathrm{km})$ \\
\hline Beijing & Shanghai & 1213 \\
\hline Beijing & Tianjin & 144 \\
\hline Beijing & Chongqing & 1763 \\
\hline Shanghai & Tianjin & 1196 \\
\hline Shanghai & Chongqing & 1971 \\
\hline Tianjin & Chongqing & 1978 \\
\hline
\end{tabular}

Table 2. Random schedule arrangement

\begin{tabular}{ccccc}
\hline round & Home court & Away court & Home court & Awaycourt \\
\hline 1 & Beijing & Shanghai & Chongqing & Tianjin \\
\hline 2 & Chongqing & Beijing & Shanghai & Tianjin \\
\hline 3 & Beijing & Chongqing & Tianjin & Shanghai \\
\hline 4 & Tianjin & Beijing & Shanghai & Chongqing \\
\hline 5 & Beijing & Tianjin & Chongqing & Shanghai \\
\hline 6 & Shanghai & Beijing & Tianjin & Chongqing \\
\hline
\end{tabular}

\section{Problem Descriptions and Assumptions}

Each city's location is described as figure1.

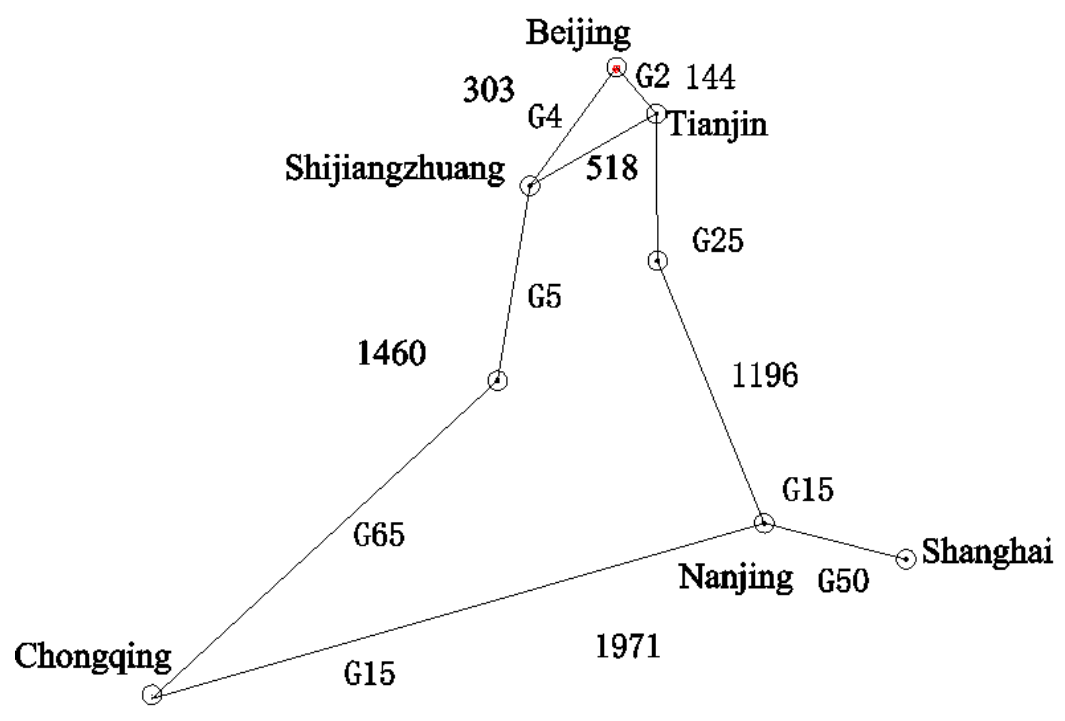

Figure1. Geographical map of different cities

To simplify programs, Beijing,Shanghai, Tianjin and Chongqing are substituted for A B C D and there will be three types[AB CD][AC BD][AD BC] respectively without considering factors such as cost, home and away. Then considering home and away but not cost, each type can be divided into four kinds of conditions, $[\mathrm{AB} C D]$ is cited as an example to explain that there are four cases: $\square[\mathrm{AB} C D][\mathrm{BA} D C] \square[\mathrm{AB} \mathrm{DC}][\mathrm{BA} C \mathrm{CD}]$, which can be divided into two groups. The feature is that groups are inseparable but mutual exclusion between groups. The number of project is $8(\mathrm{C} 1$ 2C1 2C1 2=8). To meet requirement, choosing one from $\square$, , one from $\square$ and one from $\square$ then rank them (a total of A6 6=720) and there are $5760(720 * 8=5760)$ kinds of possible cases.

Question assumptions:

1.Assuming this is the same distance from $\mathrm{A}$ to $\mathrm{B}$ and from $\mathrm{B}$ to $\mathrm{A}$.

2.Supposing the coach and fuels' consumption is constant. 
3.Assuming all positions are randomly arranged,regardless of race up and down and other factors. 4.Assuming that during the trip, there is not influence of the force majeure, all roads are impeded.

Make the first two lines of matrix M N O as a group and the second two lines as a group. Each time choose a group from M N O respectively and three groups totally as a feasible schedule. Orderly combination between six lines and there are 720 mixed combinations. Exhaustion of its overhead, MATLAB main programming is described in appendix.

\section{Result Analysis and Discussion}

Table3 The obtained optimal schedule arrangement A

\begin{tabular}{c|cc|cc}
\hline Round & Home court & Away court & Home court & Away court \\
\hline 1 & Chongqing & Beijing & Shanghai & Tianjin \\
\hline 2 & Shanghai & Beijing & Chongqing & Tianjin \\
\hline 3 & Beijing & Tianjin & Shanghai & Chongqing \\
\hline 4 & Beijing & Chongqing & Tianjin & Shanghai \\
\hline 5 & Beijing & Shanghai & Tianjin & Chongqing \\
\hline 6 & Tianjin & Beijing & Chongqing & Shanghai \\
\hline
\end{tabular}

Table4 The obtained optimal schedule arrangement B

\begin{tabular}{c|cc|cc}
\hline Round & Home court & Away court & Home court & Away court \\
\hline 1 & Chongqing & Beijing & Shanghai & Tianjin \\
\hline 2 & Shanghai & Beijing & Chongqing & Tianjin \\
\hline 3 & Beijing & Tianjin & Chongqing & Shanghai \\
\hline 4 & Beijing & Chongqing & Tianjin & Shanghai \\
\hline 5 & Beijing & Shanghai & Tianjin & Chongqing \\
\hline 6 & Tianjin & Beijing & Shanghai & Chongqing \\
\hline
\end{tabular}

After running procedure, the optimal results are shown in table3 and table4. Moreover, corresponding cities' routes are as follows:

Plan A:

Beijing $\rightarrow$ Chongqing $\rightarrow$ Shanghai $\rightarrow$ Beijing $\rightarrow$ Tianjin $\rightarrow$ Beijing

Chongqing $\rightarrow$ Shanghai $\rightarrow$ Beijing $\rightarrow$ Tianjin $\rightarrow$ Chongqing

Shanghai $\rightarrow$ Tianjin $\rightarrow$ Beijing $\rightarrow$ Chongqing $\rightarrow$ Shanghai

Tianjin $\rightarrow$ Shanghai $\rightarrow$ Chongqing $\rightarrow$ Beijing $\rightarrow$ Tianjin

Plan B:

Beijing $\rightarrow$ Chongqing $\rightarrow$ Shanghai $\rightarrow$ Beijing $\rightarrow$ Tianjin $\rightarrow$ Beijing

Chongqing $\rightarrow$ Beijing $\rightarrow$ Tianjin $\rightarrow$ Shanghai $\rightarrow$ Chongqing

Shanghai $\rightarrow$ Chongqing $\rightarrow$ Tianjin $\rightarrow$ Beijing $\rightarrow$ Shanghai

Tianjin $\rightarrow$ Shanghai $\rightarrow$ Chongqing $\rightarrow$ Beijing $\rightarrow$ Tianjin

According to the information of PCauto (http://www.pcauto.com.cn/), standardized Yutong with 55 seat coach fuels $25 \mathrm{~L}$ each hundred kilometers(0\# diesel 5.3yuan per liter).0\# sulfur content is not higher than $0.2 \%$ by GB252 and $0.15 \%$ applied this situation. The minimum fuel consumption is $5172.25 \mathrm{~L}$, sulfur dioxide emission is $15.51675 \mathrm{~kg}$ and minimum cost is 27412.925yuan. With the cost of 38870.2 yuan,the total mileage is 29336 kilometers, which can 
consume 7334L oil according to the random arrangement by game organizing committee.

According to People's Environmental Protection report on 7 September 2015, in the first half of 2015, China's overall emission of sulfur dioxide is 9.891 million tons, and motor vehicle emissions is 593460 tons, which account for about $6 \%$ of total emissions. Statistics indicated that comparing with the result of random arrangement, there are $8647 \mathrm{~km}$ reduction (or less $29.5 \%$ ), 11457.275 yuan saved and $6.50525 \mathrm{~kg}$ of sulfur dioxide decreased into atmosphere. The contribution rate of sulfur dioxide emissions decreases from $2.23 * 10^{-9}$ to $1.57 * 10^{-9}$ (decreased by $29.6 \%$ ). It provides feasible basis to improve air quality.

\section{Conclusions}

In this paper, a typical environmental problem associated with the optimal route was proposed and resolved by MATLAB. The results indicated that $8647 \mathrm{~km}$ of trip distance can be reduced in the optimal schedule arrangement compared with a random schedule arrangement. At the same time, $2161.75 \mathrm{~L}$ of fuel can be saved and $6.50525 \mathrm{~kg}$ of sulfur dioxide emission can be reduced. This study has an enlightening value to promote environmental quality and to reduce sulfur dioxide emissions.

\section{Acknowledgment}

The authors gratefully acknowledge environment engineering key subject construction of Hebei Province for their financial supports.

\section{References}

[1] Yunquan Hu.Operational research foundation and application[M],Beijing:Higher Education Press.2008:45-50 in Chinese.

[2] Yunjie Ren Numeric analysis and MATLAB achievement[M].Beijing:Higher Education Press.2007:26-45in Chinese.

[3] Mali,MATLB mathematical experiment and modeling[M].Beijing:Tsinghua University Press.2010:30-79in Chinese. 